\title{
III Congresso Internacional

\section{A INTERAÇÃO ENTRE O CICLO DA EXPERIÊNCIA DE KELLY E A SEQUÊNCIA DIDÁTICA INTERATIVA DE OLIVEIRA NO ESTUDO DOS CONCEITOS DE ÁCIDO E DE BASE NO ENSINO FUNDAMENTAL}

\author{
Apresentação: Comunicação Oral \\ Ary Figueirêdo Pessôa de Vasconcelos ${ }^{1}$; Charles Teruhiko Turuda ${ }^{2}$
}

\begin{abstract}
Resumo
Faz muitos anos que se utiliza o Ciclo da Experiência de Kelly como base teórica e estruturante para a elaboração tanto de planos de ensino quanto de projetos de pesquisa. Vinda por outro caminho, mas convergente, e embora seja mais moderna, o mesmo pode ser dito com relação à Sequência Didática Interativa. Investigações envolvendo simultaneamente as duas abordagens, entretanto, ainda são raras. O presente trabalho teve como finalidade investigativa analisar os efeitos da interação entre o Ciclo da Experiência Kellyano e a Sequência Didática Interativa tanto no ensino e na aprendizagem quanto na pesquisa em ensino de química, através de um estudo de caso. Escolhemos a tema de "ácidos e bases" para realizar isso. Usando uma metodologia associada tanto a um quanto a outro, aplicamos um conjunto de atividades de ensino a uma turma de nono ano do Ensino Fundamental de uma escola municipal de Vitória de Santo Antão - PE. Em termos de ensino, a interação mostrou-se bastante eficaz em explicitar ideias incorretas sobre os conceitos de ácido e de base e de conduzir ao aprendizado dos conceitos científicos "corretos". Em pesquisa, pudemos notar que a relação entre os dois é harmônica e nos concedeu a capacidade de detectar conceitos do senso comum conflituosos com os conceitos científicos e de analisar resultados individuais mesmo dentro de processos coletivos, vindo a confirmar que o uso simultâneo dos dois processos tem muito a contribuir para o ensino e para a pesquisa. Outro resultado obtido foi o reforço da ideia de que, quanto mais associado ao cotidiano dos estudantes determinado assunto é apresentado, mais fácil e garantida é a aprendizagem do mesmo.
\end{abstract}

Palavras-Chave: ácido, base, sequência didática interativa, ciclo da experiência kellyano.

\section{Introdução}

De acordo com Fransella (2003), há anos a Teoria dos Construtos Pessoais (TCP), criação do psicólogo norte-americano George Alexander Kelly (1905-1967), embasa pesquisas no mundo inteiro em diversas áreas e não apenas em psicologia, sua área original. Ela é uma teoria relativam entedifícil e, para compreendê-la e aplicá-la em sua plenitude, são necessários muitos anos de estudo e de aprofundamento. As ideias de construtos pessoais, matrizes de repertório, metáfora homem-cientista, sistema de construção, fragmentação, ciclo da experiência, alternativismo construtivo, dentre outras, fazem parte dessa teoria. Kelly (1955) escreveu sua obra inaugural sobre ela em dois volumes e com um total de mil duzentas e dezoito páginas! Embora seja difícil usar a

\footnotetext{
${ }^{1}$ Licenciatura Plena em Química, IFPE - campus Vitória de Santo Antão, E-mail

${ }^{2}$ Licenciado em Física, IFPE - campus Vitória de Santo Antão, charles.turuda@ vitoria.ifpe.edu.br
} 
teoria completa, alguns de seus aspectos são de entendimento e aplicação fáceis. É o caso do ciclo da experiência, usado como método de ensino e como método de pesquisa. Em seção adiante, descrevemos mais detalhadamente esse ciclo. No momento, é bastante saber que aulas e pesquisas são estruturadas seguindo suas cinco etapas e que a TCP é classificada dentro do ensino de ciências como seguindo um enfoque teórico cognitivista, de acordo com Moreira (1999).

Segundo Oliveira (2007), vindo da vertente do enfoque humanista, a Sequência Didática Interativa (SDI) é resultado das pesquisas da professora Ph.D. Maria Marly de Oliveira, atualmente docente da Universidade Federal Rural de Pernambuco, campus Garanhuns. A professora Marly pesquisou a técnica do Círculo Hermenêutico-Dialético (CHD) em seu doutorado e, alguns anos depois, desenvolveu uma sequência didática alicerçada na hermenêutica e na dialética. A SDI também tem sido base de várias pesquisas, principalmente na área de educação.

Uma das exigências para o professor é a pesquisa constante. A inovação também é necessária. Estudando as duas teorias mencionadas, pensamos em uni-las ao construir um conjunto de atividades que promovessem a aprendizagem de conceitos, tais como os de ácido e de base. Portanto, tivemos um duplo objetivo. Em ensino, alcançar a aprendizagem de conceitos de ácido e de base em uma abordagem que unisse o Ciclo da Experiência Kellyano (CEK) e a Sequência Didática Interativa (SDI). Em pesquisa, analisar os efeitos da aplicação conjunta das duas teorias tanto para a aprendizagem quanto para a própria pesquisa. Na próxima seção esclarecemos um pouco mais sobre essas duas teorias.

\section{Fundamentação Teórica}

A Teoria dos Construtos Pessoais (TCP) apresenta uma hipótese muito importante, que é a metáfora do homem-cientista (Figura 1). Para Kelly, o sistema cognitivo de todo homem funciona similarmente ao trabalho de um cientista. Todo cientista elabora previsões a partir de suas teorias e, após executar observações e experimentos, revisa sua teoria inicial instigado pelos resultados obtidos. De acordo com a TCP, qualquer homem possui um sistema de construção cognitivo a partir da qual realiza antecipações sobre eventos. Entende-se eventos como situações, pessoas ou coisas. Observando os eventos, ele pode confirmar ou refutar suas previsões e retorna para fortalecer, modificar ou substituir partes de seu sistema de construção, aprendendo desse modo. Esse processo é conhecido como "ciclo da experiência".

O Ciclo da Experiência Kellyano (CEK) constitui-se de cinco etapas pela qual o sujeito passa para que uma aprendizagem ocorra: antecipação, investimento, encontro, validação e revisão construtiva. A Figura 2 ilustra as etapas desse ciclo. 
Figura 1 - Metáfora do homem-cientista.

Fonte: Turuda (2009, p. 148).

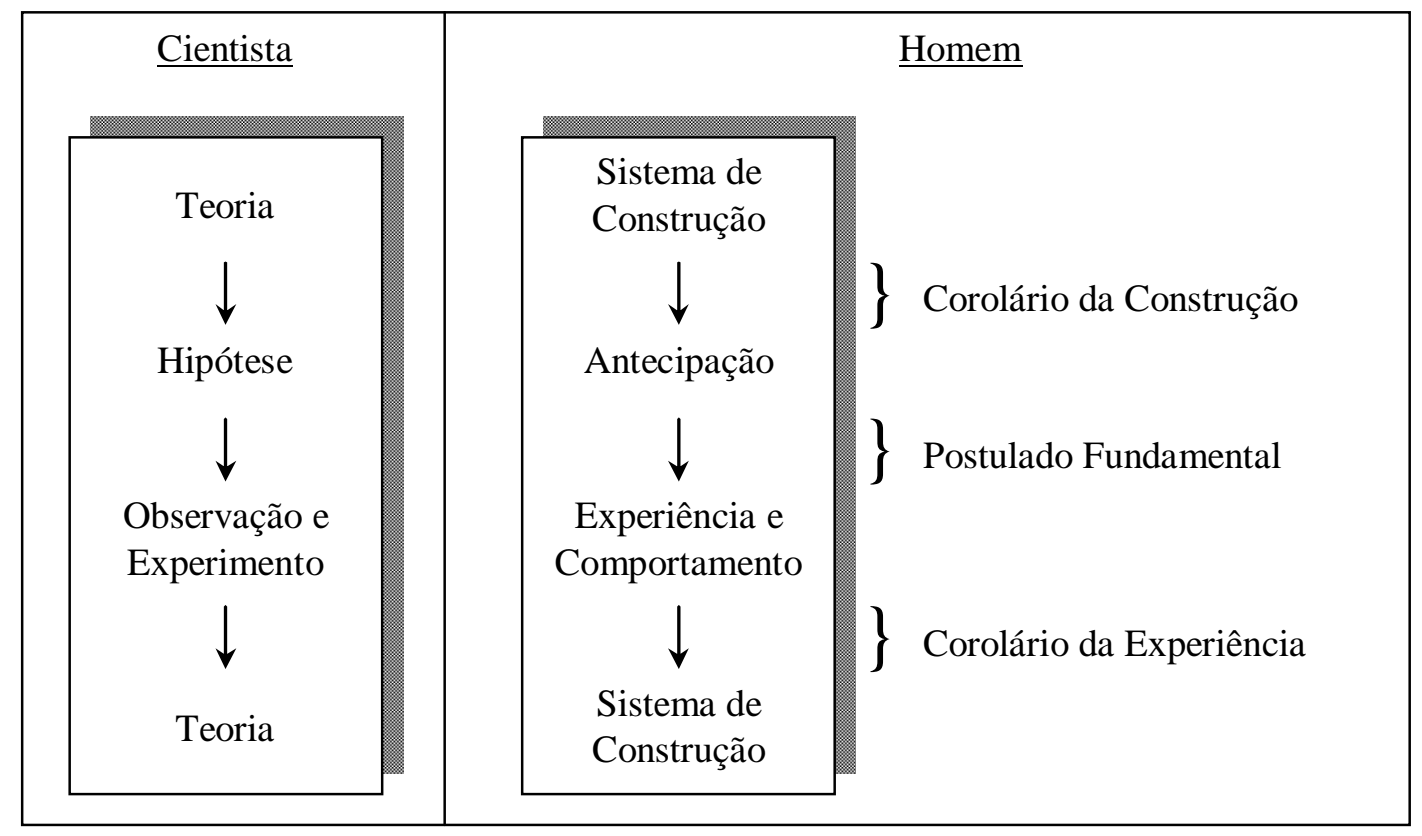

Figura 2 - O ciclo da Experiência Kellyano (CEK).

Fonte: Turuda (2009, p. 151)
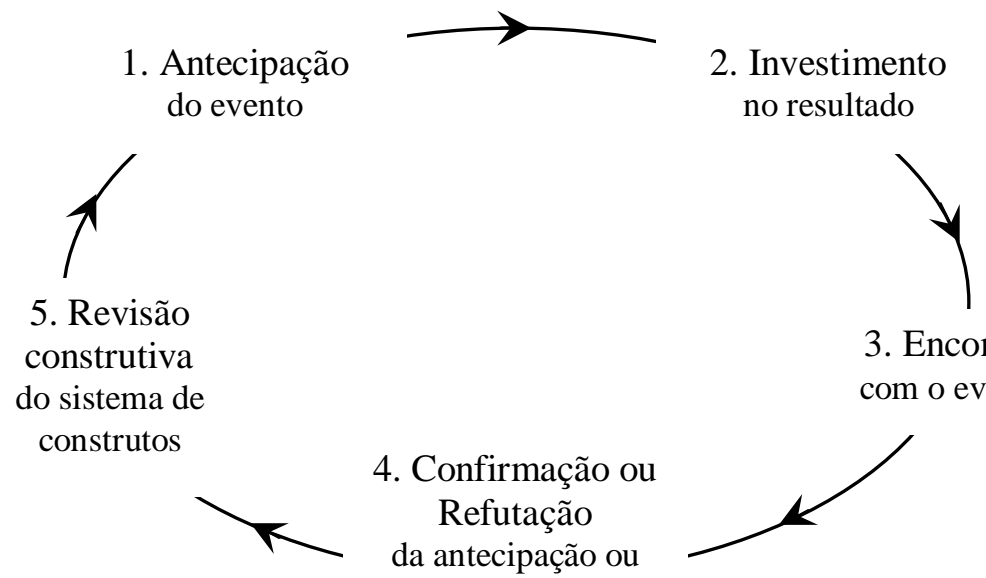

3. Encontro com o evento

4. Confirmação ou Refutação

da antecipação ou hipótese

Segundo Turuda (2009), realizaram-se diversas pesquisas na área de ensino baseadas na TCP e no CEK. Algumas dessas pesquisas aprofundaram-se na teoria, abordando os conceitos de construtos e de matrizes de repertório. Outras, como a presente investigação, utilizaram o CEK como método de pesquisa e/ou de ensino.

A Sequência Didática Interativa (SDI), por sua vez, tem sua filosofia baseada no diálogo e na intersubjetividade. Metodologicamente, pode ser aplicada seguindo-se algumas etapas. Primeiro, o indivíduo elabora uma definição particular. Em uma segunda etapa, ele a compartilha e a discute com um pequeno grupo de sujeitos e, junto com eles, elabora uma nova definição que é a definição coletiva do pequeno grupo. Em um terceiro momento, os diferentes grupos compartilham suas 
definições para elaborar uma última definição coletiva.

Figura 3 - Esquema da evolução da Sequência Didática Interativa entre os níveis de complexidade. Fonte: Própria.

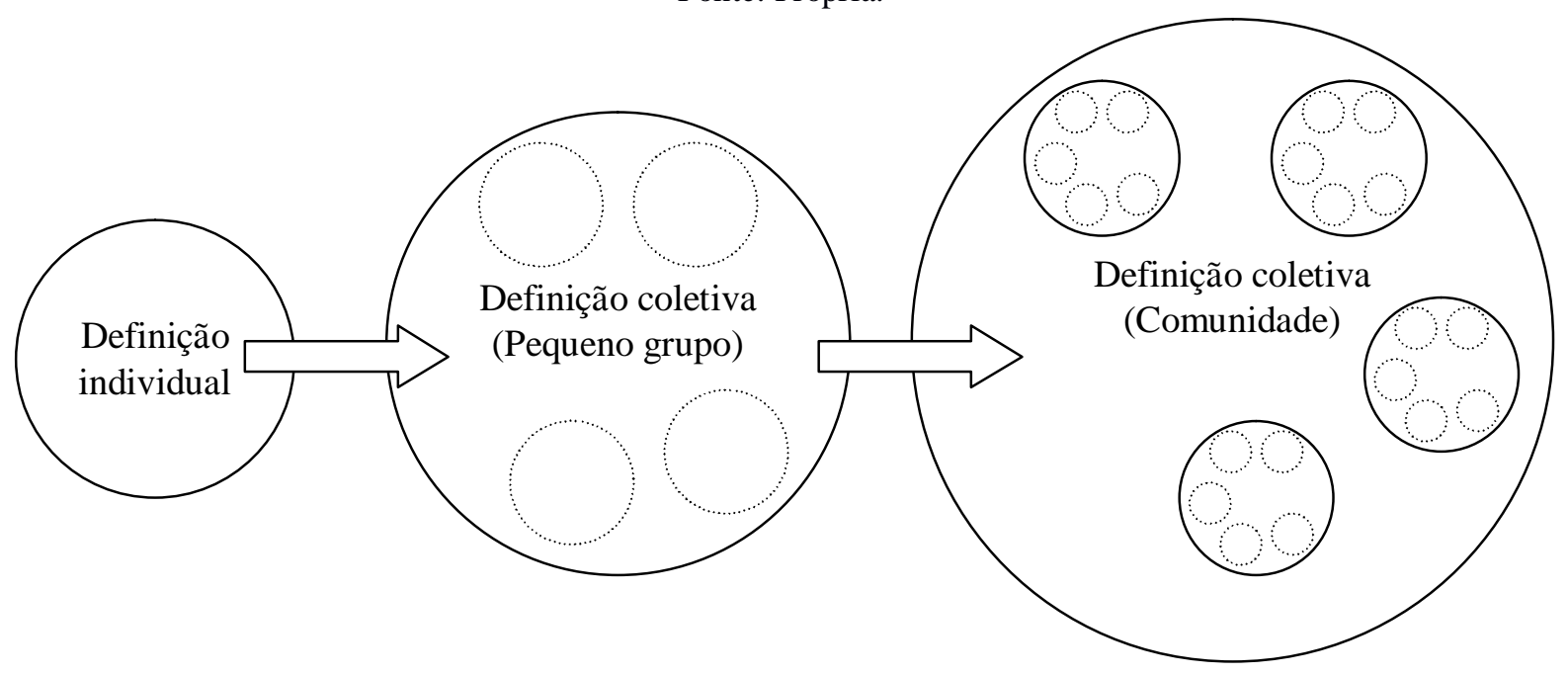

Oliveira (2007, p.124) esclarece sobre a metodologia interativa:

A metodologia interativa é um processo hermenêutico-dialético que facilita entender e interpretar a fala e depoimentos dos atores sociais em seu contexto e analisar conceitos em textos, livros e documentos, em direção a uma visão sistêmica da temática em estudo.

No presente trabalho, utilizamos o Ciclo da Experiência Kellyano associado à Sequência Didática Interativa para ensinar os conceitos de ácido e de base e pesquisar sobre essa interação.

Segundo Mahan e Myers (1995), a palavra "ácido" vem de azedo, do latim acidus. Nota-se, portanto, como o conceito de ácido está conectado ao sabor azedo. Dizem Moreno, Martins e Rajagopal (2015) que não há nenhuma função organoléptica similar para as bases e que, por isso, elas aparecem sempre em posição secundária ao se tratar a respeito de ácidos e de bases.

De acordo com Moreno, Martins e Rajagopal (2015), as definições modernas de ácido e de base mais usadas no meio científico são as teorias protônicas de J. Brønsted e T. Lowry e a teoria eletrônica de G. Lewis, mas a mais estudada nos ensinos fundamental e médio é a definição de Arrhenius. Essa definição está associada à dissociação de íons $\mathrm{H}^{+}\left(\mathrm{ou} \mathrm{H}_{3} \mathrm{O}^{+}\right)$para os ácidos e de íons $\mathrm{OH}^{-}$para as bases. $\mathrm{O}$ valor do $\mathrm{pH}$ indica acidez ou basicidade.

Mahan e Myers (1995) afirmam que os indicadores são substâncias que alteram sua cor de acordo com a concentração de íons $\mathrm{H}_{3} \mathrm{O}^{+}$presentes na solução onde se encontram e são um modo de estimar o pH de uma solução. Guimarães, Alves e Antoniosi Filho (2012) dizem que um desses indicadores está presente no extrato de repolho roxo. É a cianidina, uma substância do grupo das 
antocianinas (Figura 4).

Figura 4 - Fórmula estrutural da cianidina, o indicador de $\mathrm{pH}$ do extrato de repolho roxo.

Fonte: Wikipédia (2016). Disponível em: 〈https://en.wikipedia.org/wiki/Cyanidin\#/media/File:Cyanidin.svg〉. Acesso em: 3 out. 2016.<smiles></smiles>

A coloração do extrato de repolho roxo se altera de acordo com o pH da solução, indo do vermelho (ácido) ao amarelo (básico), passando por graduações de roxo, azul e verde (Figura 5).

Figura 5 - Coloração de soluções com extrato de repolho roxo de acordo com o pH.

Fonte: Manual da Química. Disponível em: <http://manualdaquimica.uol.com.br/experimentos-quimica/indicadoracido-base-com-repolho-roxo.htm>. Acesso em: 3 out. 2016.

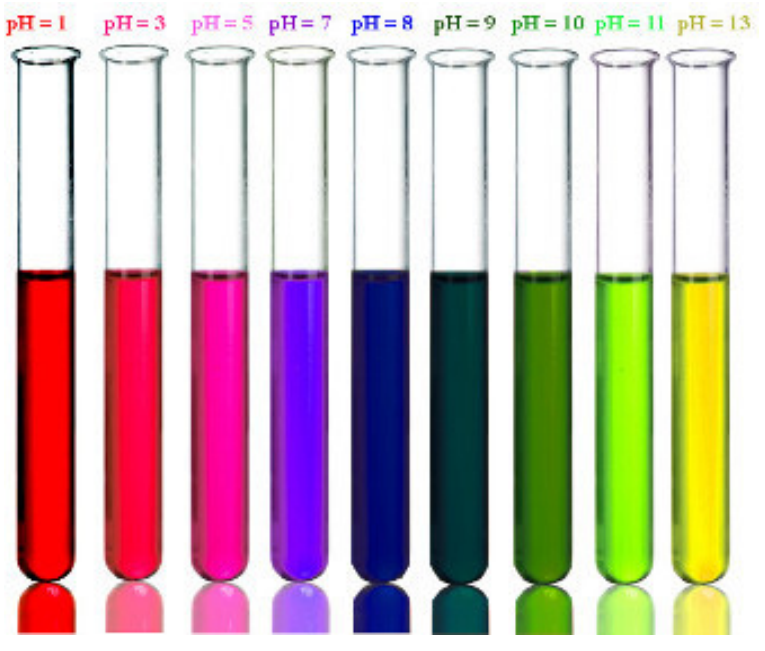

\section{Metodologia}

A presente investigação teve natureza qualitativa e foi um estudo de caso com algumas características de etnografia. O fato de se usar uma SDI corrobora com essa afirmação. Investigamos estudantes de uma turma de dezoito alunos do nono ano do Ensino Fundamental de uma escola municipal de Vitória de Santo Antão, PE. Embora a instituição de ensino seja urbana, a maioria dos estudantes da turma investigada tem moradia na zona rural do município. Esses estudantes já tinham estudado teoricamente as definições de Arrhenius para ácidos e bases. Para ácidos, o exemplo típico dado foi o ácido clorídrico $(\mathrm{HCl})$ e, para bases, o hidróxido de sódio $(\mathrm{NaOH})$. Também estudaram anteriormente o conceito de indicador, tendo o tornassol e a fenolftaleína como exemplos típicos.

Para a construção dos dados, utilizamos questionários e observações. Dois pesquisadores 
estavam presentes no dia da aplicação do questionário inicial. Um pesquisador ficou responsável por aplicar os procedimentos da sequência didática proposta e o outro ficou responsável por registrar as observações dos sujeitos de pesquisa.

Inicialmente, distribuíram-se cartões de tamanho A6 em branco para que os sujeitos escrevessem individualmente a resposta para duas questões:

a) Dada uma substância X, como você identificaria se ela é ácida?

b) Cite exemplos de substância ácida.

Depois, a turma dividiu-se em pequenos grupos de três, quatro ou cinco estudantes. Eles leram suas respostas individuais para os demais componentes do grupo e discutiram entre si para elaborar uma resposta única das mesmas questões e que representasse, ao máximo, um consenso entre eles. Os grupos elegeram um representante para ler as respostas coletivas para a turma toda e isso foi realizado. Deve-se notar que essa parte da pesquisa foi estruturada de acordo com uma Sequência Didática Interativa.

$\mathrm{Na}$ segunda fase, os alunos se agruparam nas mesmas formações. Os grupos receberam os seguintes materiais: cinco copos descartáveis contendo substâncias diferentes - água sem gás, água gaseificada, água sanitária, detergente neutro e vinagre - e um recipiente contendo extrato de repolho roxo, que serviu no experimento como indicador. Escreveu-se no quadro as seguintes informações sobre as cores do indicador usado no experimento:

$$
\begin{gathered}
\text { vermelho } \rightarrow \text { ácido } \\
\text { roxo } \rightarrow \text { neutro } \\
\text { azul } \rightarrow \text { fracamente básico } \\
\text { verde e amarelo } \rightarrow \text { básico }
\end{gathered}
$$

Cada aluno escreveu uma previsão de cor para cada substância e, depois, os grupos adicionaram o extrato de repolho roxo nas substâncias para ver e anotar a cor observada. Os alunos preencheram os relatórios de observação e também relataram oralmente, quando perguntados, sobre diferenças entre o previsto e o observado logo após a atividade experimental. Esta parte da metodologia envolve, para os estudantes, pelo menos um Ciclo da Experiência Kellyano. Ao realizar o experimento, os alunos estão se encontrando com o evento e confirmando ou refutando suas previsões. Se houver refutação, haverá modificação do sistema de construção, o que implica aprendizagem.

Finalizou-se a atividade pedindo-se que os alunos identificassem, através da análise com o indicador, se uma substância, entregue pelos pesquisadores e não identificada, era um ácido ou uma base. Eles realizaram o teste e deram o resultado do mesmo. 
Nossas análises iniciais das respostas ao primeiro questionário e algumas observações que realizamos durante a aplicação desse e da atividade experimental causaram-nos algumas dúvidas. Dentre elas, se havia ficado a ideia correta de que refrigerantes em geral são ácidos devido à presença de água gaseificada em sua composição. Essa dúvida ocorreu porque detectamos que alguns alunos previram erroneamente que água com gás fosse uma base, mesmo apontando um refrigerante de cola como ácido em fase anterior. Então, aplicamos mais um questionário em outro dia, dessa vez propondo as seguintes questões:

a) Caso fosse apresentado para análise de $\mathrm{pH}$ um refrigerante sabor guaraná, você o classificaria como: ácido, neutro ou básico?

b) Justifique sua resposta anterior.

Utilizamos o guaraná na pergunta, porque o sabor dele não costuma ser considerado azedo. A primeira pergunta tinha a intenção de verificar se haviam generalizado que todos os refrigerantes são ácidos e a segunda pergunta verificou se associavam a causa à gaseificação da água.

Para tirar outras dúvidas geradas pelo primeiro questionário, pedimos também para dois sujeitos que citaram a gasolina e dois que citaram o polidor como substância ácida para justificarem suas respectivas respostas anteriores. A intenção foi esclarecer a interpretação a ser dada para essas.

Em nossas análises, verificamos as diferenças entre as respostas esperadas e observadas do relatório de observação. Consideramos as respostas "lilás", "roxo" e "roxo fraco" como pertencentes à mesma categoria. Comparamos as previsões para água gaseificada com exemplos contendo o termo "refrigerante" dados no questionário inicial. Anotamos, estudamos e categorizamos diferenças entre as respostas individuais e as coletivas.

$\mathrm{Na}$ próxima seção apresentamos os resultados obtidos. Para preservar o anonimato dos alunos, renomeamo-nos aleatoriamente por A1, A2, A3, .., A18. A tabela a seguir mostra os grupos a que pertenceram cada um deles.

Tabela 1 - Composição dos grupos.

Fonte: Própria.

\begin{tabular}{|c|c|}
\hline GRUPO & COMPOSIÇÃO \\
\hline G1 & A1, A8, A13, A14 e A17 \\
\hline G2 & A3, A5 e A11 \\
\hline G3 & A6, A16 e A18 \\
\hline G4 & A4, A7 e A9 \\
\hline G5 & A2, A10, A12 e A15 \\
\hline
\end{tabular}




\section{Resultados e Discussão}

A Tabela 2 mostra a categorização dos resultados para a primeira questão do primeiro questionário a respeito do processo de identificação de ácidos. Um mesmo aluno pode pertencer a mais de uma categoria porque houve respostas múltiplas.

Tabela 2 - Categorização das respostas à primeira questão.

Fonte: Própria.

\begin{tabular}{|c|c|}
\hline CATEGORIA & ALUNOS \\
\hline Uso de indicadores & $\mathrm{A} 2, \mathrm{~A} 4, \mathrm{~A} 6, \mathrm{~A} 7, \mathrm{~A} 8, \mathrm{~A} 9, \mathrm{~A} 10, \mathrm{~A} 12, \mathrm{~A} 13, \mathrm{~A} 14, \mathrm{~A} 15, \mathrm{~A} 16, \mathrm{~A} 17$ e A18 \\
\hline Ver $\mathrm{pH}$ & $\mathrm{A} 1, \mathrm{~A} 3$ e A11 \\
\hline Comendo se for comida & $\mathrm{A} 5$ \\
\hline Provando & $\mathrm{A} 17$ \\
\hline Jogando no chão & $\mathrm{A} 4$ \\
\hline
\end{tabular}

A Figura 6 mostra as respostas individuais dos alunos A4, A7 e A9 e a resposta coletiva que construíram como membros do grupo G4.

Figura 6 - Respostas do grupo G4 para a questão sobre identificação de ácidos.

Fonte: Própria.

A4: "Eu jougaria $[s i c]$ um pouco no chão".

A7: "Usando fenolftaleína ou tornassol".

G4: "Jogando um pouco no chão para indentificar [sic] ou usando fenolftaleína ou tornassol".

A9: "Usando fenolftaleína ou tornassol".

O processo de construção de outros grupos foi bastante similar ao que ocorreu com esse grupo. O que fizeram foi apenas juntar o que cada um escreveu, sem, talvez, refletir sobre conflitos entre as respostas.

Para a questão dos exemplos de ácidos, muitos citaram frutas de sabor azedo, tais como limão, abacaxi e laranja. Alguns citaram o vinagre e vários citaram um refrigerante de cola. Somente dois alunos lembraram-se de citar o exemplo típico dado pelo professor deles: o ácido clorídrico. E esse é citado pela fórmula química: $\mathrm{HCl}$. Parece ser uma indicação de como é mais fácil aprender o conceito de ácido quando o mesmo está associado a elementos do cotidiano.

A Tabela 3 mostra todos os resultados obtidos para a cor esperada e a cor observada para a água gaseificada e a água sanitária. Nota-se que apenas o aluno A16 acertou a previsão para a água gaseificada e que somente os alunos A2, A10 e A15 acertaram para a água sanitária. 
Tabela 3 - Comparação entre a cor esperada e a cor observada para a água gaseificada e a água sanitária. Fonte: Própria.

\begin{tabular}{|c|c|c|c|}
\hline \multirow{19}{*}{ Água gaseificada } & ALUNO & COR ESPERADA & COR OBSERVADA \\
\hline & $\mathrm{A} 1$ & Vermelho & Roxo fraco \\
\hline & $\mathrm{A} 2$ & Amarelo & Lilás \\
\hline & A3 & Vermelho & Roxo fraco \\
\hline & $\mathrm{A} 4$ & Verde & Roxo claro \\
\hline & A5 & Vermelho & Roxo claro \\
\hline & A6 & Verde & Roxo fraco \\
\hline & A7 & Azul & Roxo fraco \\
\hline & A8 & Azul & Roxo claro \\
\hline & A9 & Azul & Roxo fraco \\
\hline & A10 & Amarelo & Lilás \\
\hline & A11 & Vermelho & Roxo fraco \\
\hline & A12 & Amarelo & Lilás \\
\hline & A13 & Azul & Roxo fraco \\
\hline & A14 & Azul & Roxo fraco \\
\hline & A15 & Amarelo & Lilás \\
\hline & A16 & Roxo & Roxo \\
\hline & A17 & Azul & Roxo fraco \\
\hline & A18 & Verde & Roxo fraco \\
\hline \multirow{18}{*}{ Água sanitária } & A1 & Vermelho & Amarelo \\
\hline & $\mathrm{A} 2$ & Amarelo & Amarelo \\
\hline & A3 & Vermelho & Amarelo \\
\hline & A4 & Vermelho & Amarelo \\
\hline & A5 & Vermelho & Amarelo \\
\hline & A6 & Vermelho & Amarelo \\
\hline & A7 & Vermelho & Amarelo \\
\hline & A8 & Vermelho & Amarelo \\
\hline & A9 & Vermelho & Amarelo \\
\hline & A10 & Amarelo & Amarelo \\
\hline & A11 & Vermelho & Amarelo \\
\hline & A12 & Amarelo & Amarelo \\
\hline & A13 & Vermelho & Amarelo \\
\hline & A14 & Vermelho & Amarelo \\
\hline & A15 & Amarelo & Amarelo \\
\hline & A16 & Azul & Amarelo \\
\hline & A17 & Vermelho & Amarelo \\
\hline & A18 & Azul & Amarelo \\
\hline
\end{tabular}

O caso da água sanitária chamou nossa atenção. Doze dos dezoito sujeitos de pesquisa anteciparam que a mesma seria um ácido, colocando "vermelho" como cor prevista. A fala não gravada, mas registrada pelos pesquisadores, de um dos alunos, talvez expresse a ideia por trás do erro com a previsão para a água sanitária: “água sanitária queima, só pode ser um ácido”. Nesse caso, a palavra "queima" está associada à sensação de ardor. Portanto, detectamos a ideia do senso comum de que a sensação de ardor é uma característica de substâncias ácidas. 
As previsões para a cor da solução de detergente com adição do indicador apresentaram pouca variação (Tabela 4). A maioria dos alunos esperava uma cor verde, correspondente a uma base, e observou um pH neutro. O que é interessante notar é que, embora fizessem parte de um mesmo grupo de observação, alguns alunos (A4, A5 e A9) escreveram expectativas pessoais diferentes do coletivo, não se deixando afetar pela opinião diferente de outros membros de seu grupo.

Tabela 4 - Comparação entre cor esperada e cor observada para a solução de detergente.

Fonte:Própria.

\begin{tabular}{c|c|c}
\hline ALUNOS & COR ESPERADA & COR OBSERVADA \\
\hline $\begin{array}{c}\mathrm{A} 1, \mathrm{~A} 2, \mathrm{~A} 3, \mathrm{~A} 6, \mathrm{~A} 7, \mathrm{~A} 8, \mathrm{~A} 10, \mathrm{~A} 11, \mathrm{~A} 12, \\
\mathrm{~A} 13, \mathrm{~A} 14, \mathrm{~A} 15, \mathrm{~A} 16, \mathrm{~A} 17\end{array}$ & Verde & Roxo \\
\hline $\mathrm{A} 4$ & Azul & Roxo \\
\hline $\mathrm{A} 5$ & Roxo & Roxo \\
\hline $\mathrm{A} 9$ & Amarelo & Roxo \\
\hline
\end{tabular}

Para a solução de água sem gás, os resultados variaram bastante (Tabela 5), mas uma quantidade maior de sujeitos deu um resultado considerado correto: roxo. A água é uma substância tipicamente neutra e dada como exemplo em sala de aula. Novamente notamos a independência das respostas individuais de alguns sujeitos. O aluno A15 pertence ao mesmo grupo dos alunos A2, A10 e A12, mas discordou na previsão realizada por esses.

Tabela 5 - comparação entre a cor esperada e a cor observada para a água sem gás. Fonte: Própria.

\begin{tabular}{c|c|c}
\hline ALUNOS & COR ESPERADA & COR OBSERVADA \\
\hline $\mathrm{A} 1, \mathrm{~A} 3, \mathrm{~A} 4, \mathrm{~A} 5, \mathrm{~A} 6, \mathrm{~A} 7, \mathrm{~A} 9, \mathrm{~A} 11, \mathrm{~A} 15, \mathrm{~A} 18$ & Roxo & Roxo \\
\hline $\mathrm{A} 2, \mathrm{~A} 10, \mathrm{~A} 12$ & Azul & Lilás \\
\hline $\mathrm{A} 8$ & Verde & Azul \\
\hline $\mathrm{A} 13, \mathrm{~A} 14$ & Amarelo & Azul \\
\hline $\mathrm{A} 16$ & Amarelo & Roxo \\
\hline $\mathrm{A} 17$ & Roxo & Azul \\
\hline
\end{tabular}

Para a solução com vinagre, as respostas foram unânimes e corretas: o vinagre é um ácido.

Retornemos um pouco, pois é bastante interessante analisar as respostas do grupo G1, formado pelos alunos A8, A13 e A14. O aluno A8 citou a "gasolina" e os alunos A13 e A14 citaram o "polidor" como exemplo de ácido em suas respostas individuais. Na resposta coletiva do grupo, entretanto, o polidor desapareceu dos exemplos citados, permanecendo a gasolina. Em nossa investigação, não foi importante saber se a gasolina e o polidor são mesmo ácidos ou não. Importou-nos, enquanto pesquisadores, saber por que os alunos acharam isso. A presença da gasolina como exemplo de ácido parece dever-se à mesma ideia de ardor expressa anteriormente. Outra ideia que apareceu associada à acidez foi a capacidade de provocar algum tipo de corrosão, 
no caso do polidor. As respostas dos alunos do grupo G4 sobre como identificar um ácido, e que estão reproduzidas na Figura 6, contribuem com essa interpretação. A corrosão provocada pela substância ao ser atirada no chão seria um teste para identificar substâncias ácidas.

As justificativas dos alunos A13 e A14 para o fato de polidor ser ácido estão transcritas, respectivamente, a seguir: "Porque ele limpa as panelas então eu acho que é ácido" e "Porque ele limpa as panelas por isso eu acho que é ácido". Elas continuam apontando na direção da ideia de capacidade de corrosão estar associada ao conceito de ácido.

Metade dos alunos respondentes citou um famoso refrigerante a base de cola como exemplo de ácido. Entretanto, apenas um deles acertou a previsão da água gaseificada ser um ácido na etapa com uso do indicador. Diante das previsões incorretas com relação à água gaseificada e sua incompatibilidade com a citação do refrigerante à base de cola como ácido, preocupamo-nos em saber se os alunos haviam aprendido que parte da acidez em refrigerantes deve-se ao fato de a água ser gaseificada. O segundo questionário aplicado mostrou uma resposta positiva quanto à aprendizagem. Todos os respondentes disseram que o refrigerante sabor guaraná é um ácido. Dentre as justificativas, encontramos respostas como a apresentada na Figura 7: "Porque a água com gás é [um] ácido e o guaraná é bem semelhante, então eu acho que também é ácido”.

Figura 7 - Justificativa do sujeito de pesquisa A13 para o fato de refrigerante sabor guaraná ser ácido.

Fonte: Própria.

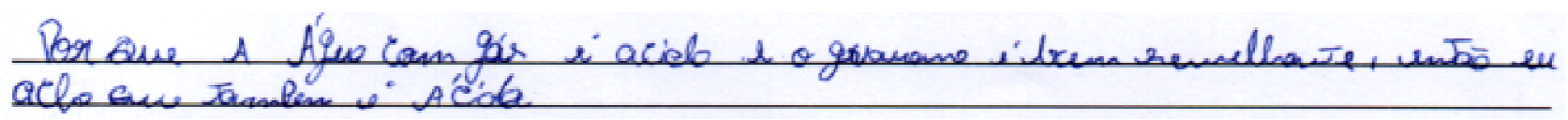

\section{Conclusões}

Pudemos perceber o quanto a interação entre o Ciclo da Experiência Kellyano e a Sequência Didática Interativa é produtiva tanto para o ensino quanto para a pesquisa. Essa interação permitiu a detecção de conceitos do senso comum, a possibilidade de discutir esses conceitos com os estudantes e de "corrigi-los" para conceitos mais científicos, capacitou a análise da aprendizagem em conjunto e individualmente. Além disso, pelos registros fotográficos (Figura 8), é possível notar o grande envolvimento e interesse despertados pelas atividades nos discentes.

Durante nossas análises, lembramo-nos de que a maioria dos estudantes pesquisados é da zona rural do município. Pareceu-nos, então, natural que citassem frutas como exemplo de ácidos. Isso reforça a ideia de que, quanto mais o assunto estudado está associado ao cotidiano, mais significativo é a sua aprendizagem. Os estudantes quase não citaram o ácido clorídrico ( $\mathrm{HCl})$, exemplo de ácido típico dado na escola. Até porque seu nome coloquial é outro

A proposta superou nossas expectativas. Kelly parece estar correto ao afirmar que todos nós 
passamos pelo CEK. Acreditamos que nós, pesquisadores, também aprendemos muito com essa atividade. Revisamos muito de nosso sistema de construção após o encontro com o evento, - a pesquisa e a aula, - e acreditamos agora que muita coisa será prevista de modo diferente.

Figura 8 - Fotografias da atividade experimental. Fonte: Própria.
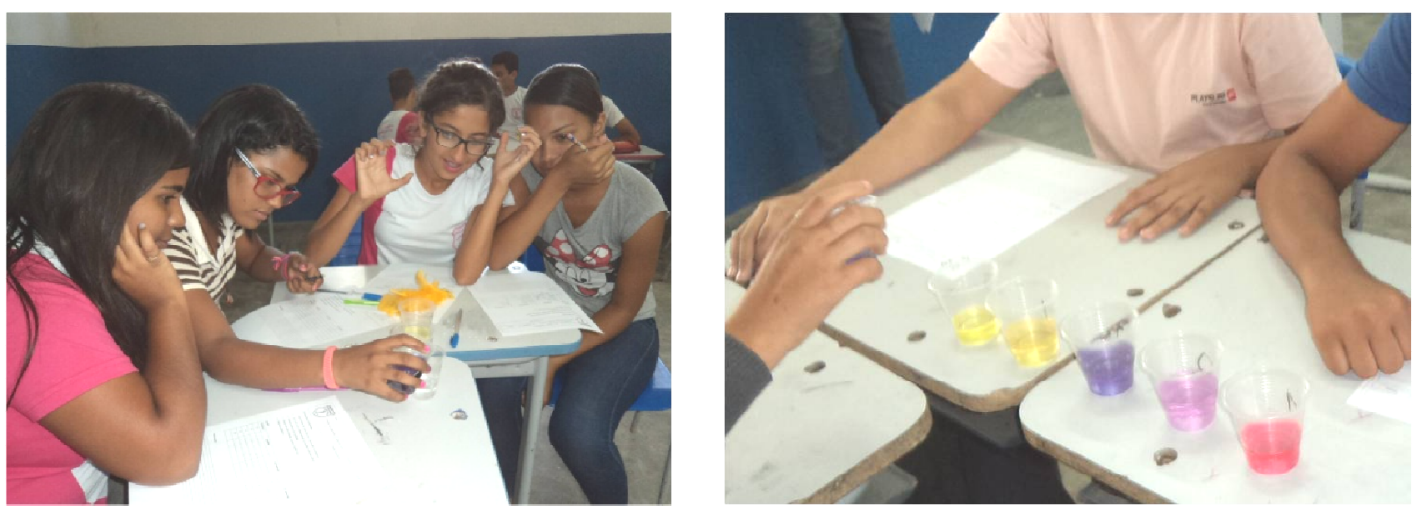

\section{Referências}

FRANSELLA, Fay (Editor). International handbook of personal construct psychology. Chichester, Inglaterra: John Wiley \& Sons Ltda, 2003.

GUIMARÃES, W.; ALVES, M. I. R.; ANTONIOSI FILHO, N. R. Antocianinas em extratos vegetais: aplicação em titulação ácido-base e identificação via cromatografia líquida/espectrometria de massas. In: Química Nova, v. 35, n. 8, p. 1673-9, 2012.

KELLY, George A. The psychology of personal constructs: a theory of personality. Nova Iorque, EUA: Norton \& company, 1955. 1218 p.

MAHAN, B. M.; MYERS, R. J. Química: um curso universitário. Trad. da 4a. ed. americana. São Paulo: Blucher, 1995.

MOREIRA, Marco Antonio. Teorias de aprendizagem. São Paulo: EPU, 1999. 195 p.

MORENO, E. L.; MARTINS, E.; RAJAGOPAL, K. Basicidade e acidez, da pré-história aos dias atuais. In: Revista Virtual de Química, v. 7, n. 3, p. 893-902, 2015.

OLIVEIRA, M, M. de. Como fazer pesquisa qualitativa. Petrópolis, RJ: Vozes, 2007.

TURUDA, C. T. A teoria dos construtos pessoais nas pesquisas em Ensino das Ciências da Universidade Federal Rural de Pernambuco. In: OLIVEIRA, M. M. de (Org.). CTSA: experiências multi e interdisciplinares no Ensino de Ciência e Matemática. Recife: Ed. do Organizador, 2009. 